\title{
Parklet: A New Urban Platform for Emergent Forms of Communication and Social Interaction in the Cities
}

\author{
Mona Ghandi ${ }^{*}$ \\ ${ }^{1}$ Assistant Professor, Department of Architecture, Washington State University, United States \\ *Corresponding author's e-mail: mona.ghandi@wsu.edu
}

\begin{abstract}
Social interaction is critical to the physical and intellectual well-being of a functioning democracy. The excessive influence of technology and lack of urban design and planning's attention to pedestrian experience has caused our interactions to become more private, isolated, and mostly virtual. The following project presents the product of a design-build studio which uses adaptive/Kinetic systems to generate a creative solution to this social problem. Specifically, it will showcase the efforts of students working on a Parklet project, repurposing urban space to advance local business ethics and social justice issues. The Parklet replaces a parking space, fostering increases in social connections, public vibrancy, and support for local businesses. To move beyond schematic design, and offer students an experiment in real-world design issues, this studio provided a hands-on atmosphere for collaborative and consensus design experience, learning-by-doing, detailing challenges, and offsite construction strategies. It was structured to promote lessons in collaboration, construction detailing and process, and adaptive design, including working with city officials to meet code and zoning regulations. Since the project's site is located in a neighboring city, students prefabricated the pieces in school and shipped and assembled them on site in one day. The studio sought to promote CAAD education, teaching design, and construction, but also innovation and entrepreneurship, through computational technology. The pedagogical framework was defined around various considerations such as structural, functional, financial, aesthetical, technological, and collaboration with other disciplines such as structural engineering and construction management.
\end{abstract}

\section{KEYWORDS}

CAAD Education and teaching; Collaborative Design-Build project; Service Learning and Community Engagement; Computational Design and Digital fabrication; Transformable Structures; Offsite Construction; Social Architecture; Digital Simulation

\section{INTRODUCTION}

A fundamental feature of life is social interaction. This means that all individuals, except those who choose to live truly alone, have daily physical or virtual interaction with other individuals. Social interaction is a critically important contributor to good health and longevity. As the Harvard Women's Health Watch reported, "Dozens of studies have shown that people who have satisfying relationships with family, friends and their community are happier, have fewer health problems, and live longer." (Harvard Health Publishing, 2010) 
Through the last half century, streets in the big cities have gone through transformations that have rarely been in favor of the pedestrian experience. As demonstrated in the works of Donald Appleyard (1973), Mike Davis (1990/2006), Jane Jacobs (1961) Douglass Lee (1973), Serge Chermayeff and Christopher Alexander (1963) and others, urban design and planning's attention has been geared to mostly accommodate automobiles than pedestrians to the extent that we are now witnessing its devastating social effects. Lack of social interaction and communication between citizens is a critical contemporary socio-economic issue. This has caused our communities to become more private, isolated, and mostly virtual. It is obvious that the role that urban spaces play in fostering social interaction and dynamic relations is prominent and significant.

It is only in recent years that a thriving group of designers, community activists and government facilitators with a passion for social and environmental equity and pedestrian-centered design experiments have stepped forward to advocate for a new perception of streetscapes. For example, Spacebuster by Raumlabor was developed and designed to explore the qualities and possibilities of public space in New York City. It activates the untapped potential of abandoned, leftover or in transition urban sites and transforms them into new vibrant urban spaces through Multi-facetted usage of space.

In the last couple of years, two community experimental actions and urban interventions were formed to solve this lack of interaction by redressing the urban fabric: Parklet and Pedestrian Plaza. Parklet occupies parking spots or loading zones, serving as an extension to sidewalks and Pedestrian Plaza reclaim excess roadways, often at irregular intersections. The two together have introduced "Heuristic Urbanism" known as a collaborative endeavor to rejuvenate urban design through continuously self-evaluating programs and projects that are dynamic and provisional (Abad Ocubillo 2012). They are tactical responses to the social dysfunction of our streets (SadikKhan 2011, Seligman 2011).

The focus of Parklets is on people. They offer a place to rest, sit, and stop while taking in the activities of the street. They often include greenery, art installation, bicycle parking, and games (Abad Ocubillo 2012). These urban social platforms and temporary sidewalk extensions provide more space and amenities for people using the street (San Francisco Parklet Manual 2013). By covering a parking space and turning it into public use, they raise social connections, increase public vibrancy, and support local businesses. Such urban gathering spaces in the cities give people a chance to appreciate the value of making and maintaining social connections, increasing the vibrancy of the public realm, generating pedestrian activity, and activating new uses for streets. These public spaces in the neighborhoods not only benefit the people but also work as attractor points for the neighborhood and local businesses. They pull forgotten areas of the city back into action, enlivening them with informal gatherings and social activity.

It was in California that the Parklet was pioneered, specifically in the San Francisco Bay Area where the first Parklet got built by Suzi Bolognese (Sb Design Studio) in 2010 (Inhabitat 2014). The idea has gone on to enliven countless blocks around the world and nowadays we can see many Parklets in other cities such as Los Angeles, New York, Spokane, Ames, Iowa, Sao Paulo, and, Mexico city (Grunewald 2013). Although a Parklet can be permanent, it should be designed for quick and easy removal, during times when of emergency, snows removal, etc. (Miller, 2012)

Along with the perceptional change in the contemporary urban design, advances in computational algorithmic design, material science, and fabrication technologies have exposed architects to new opportunities in design enabling them to address such contemporary needs of cities and citizens through creative design solutions. The paper presents the pedagogical approach in introducing 
computational design and digital fabrication potentials to third-year undergraduate students through the real-world applications of such technologies. It presents a product of a design-build studio which uses emerging technologies and adaptive systems to generate a solution, a Parklet, to help society and community.

This studio investigated the impact of new technologies on architectural education and practice, in advancing innovative design strategies, and alternating the methods of building delivery and construction process of this project. It sought to promote learning of new methods of design and construction grounded in computational design and digital fabrication to optimize the design, lower the cost, and ease up the construction process.

\section{METHODOLOGY}

This studio was based on a design-build method, exposing students to direct encounters with physical construction, collaborative techniques and new forms of design knowledge introduces by collaborative construction. To move beyond schematic design, and offer students an experiment on real-world design issues, this studio provided a design-build endeavor and collaborative and consensus design experience. It made possible lessons in learning-by-doing, detailing challenges, and construction strategies. In a pedagogical framework, this studio encouraged student innovation and enhanced students' perception of design computation, mechanisms, and human behavior as they address critical contemporary and future social issues. The pedagogical framework was defined around various considerations helping students overcome challenges in construction know-how, construction management, structural/engineering specifications, city rules and regulations, budgeting, client interaction, material properties, and collaboration with students in other disciplines such as engineering and construction management.

In order to create a collaborative studio, throughout the semester, 14 Junior undergraduate students were grouped in teams of two. They participated in design charrettes, took field trips, and presented design solutions. External consultations with structural engineering and construction management students were conducted to enhance the design and fabrication solutions. Serving as a bridge between education and professional practice, this studio provided a creative academic environment punctuated by regular review sessions with industry partners, city council, local businesses, and residents of the neighborhood.

Taking advantage of new visualization and analysis technologies, students were able to collaboratively design 7 Parklets and build one full-scale Parklet in Spokane. The pedagogical steps followed in the class are as follows:

\section{Phase 1: Research}

In the first phase, students were introduced to their clients, context/site, and available literature review to explore the potentials embedded in emergent technologies. They researched and analyzed precedents, explored applications for flexible and multi-functional spaces and synthesized an outcome for designing transformable Parklet in two weeks. Students used cuttingedge digital software for design development, analysis, and making a series of flexible and kinetic structures. (Figure 1) 


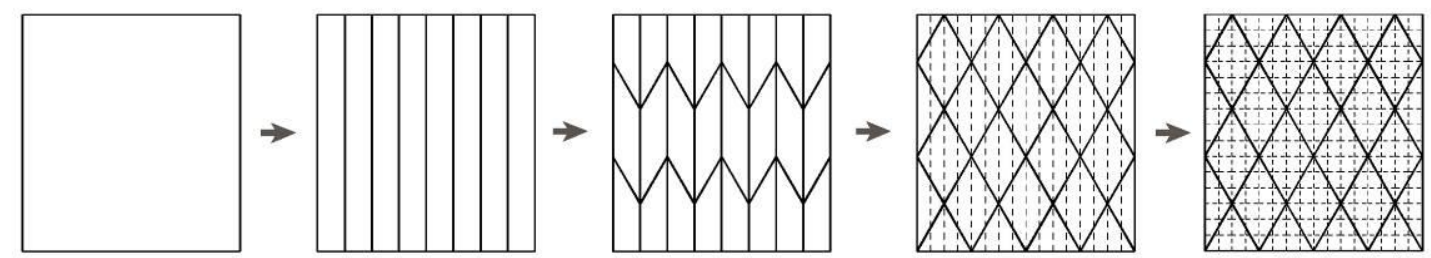

step 1

step 2

step 3

step 4

step 5
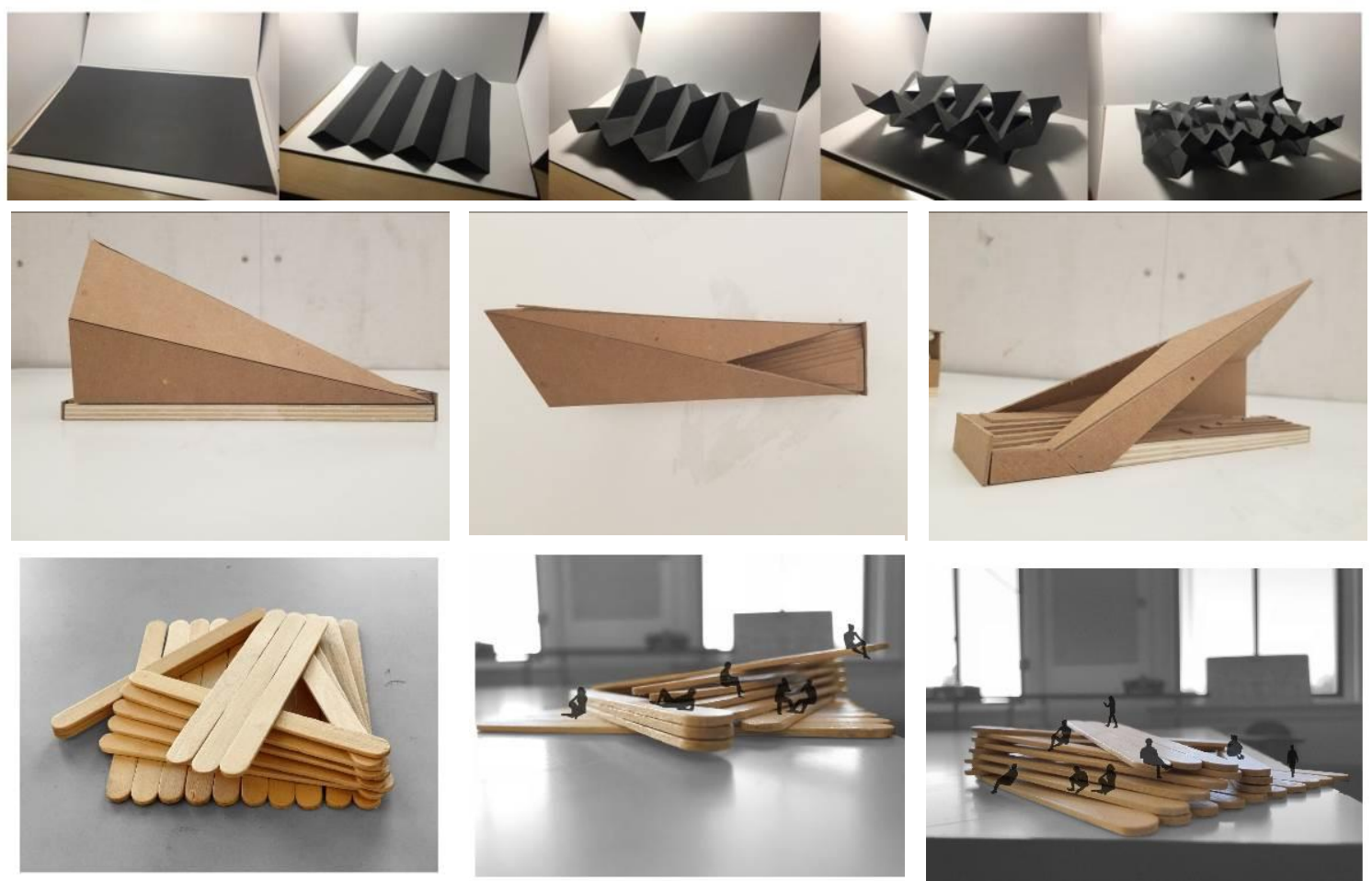

Figure 1. Students' investigation on possibilities in computational design and material behavior for designing a series of flexible and kinetic structures.

\section{Phase 2: Design Exploration}

Working in groups of two, students designed 7 transformable Parklets, in accordance with site analysis, city regulations, existing businesses, neighborhood programmatic needs, and available budget. In one and a half month, they designed multi-functional Parklets that will be used permanently and could be uninstalled and reinstalled when needed. In the end, jurors from the professional community and students selected one project to be built in full-scale. Below you can see the selected project. (Figure 2) 

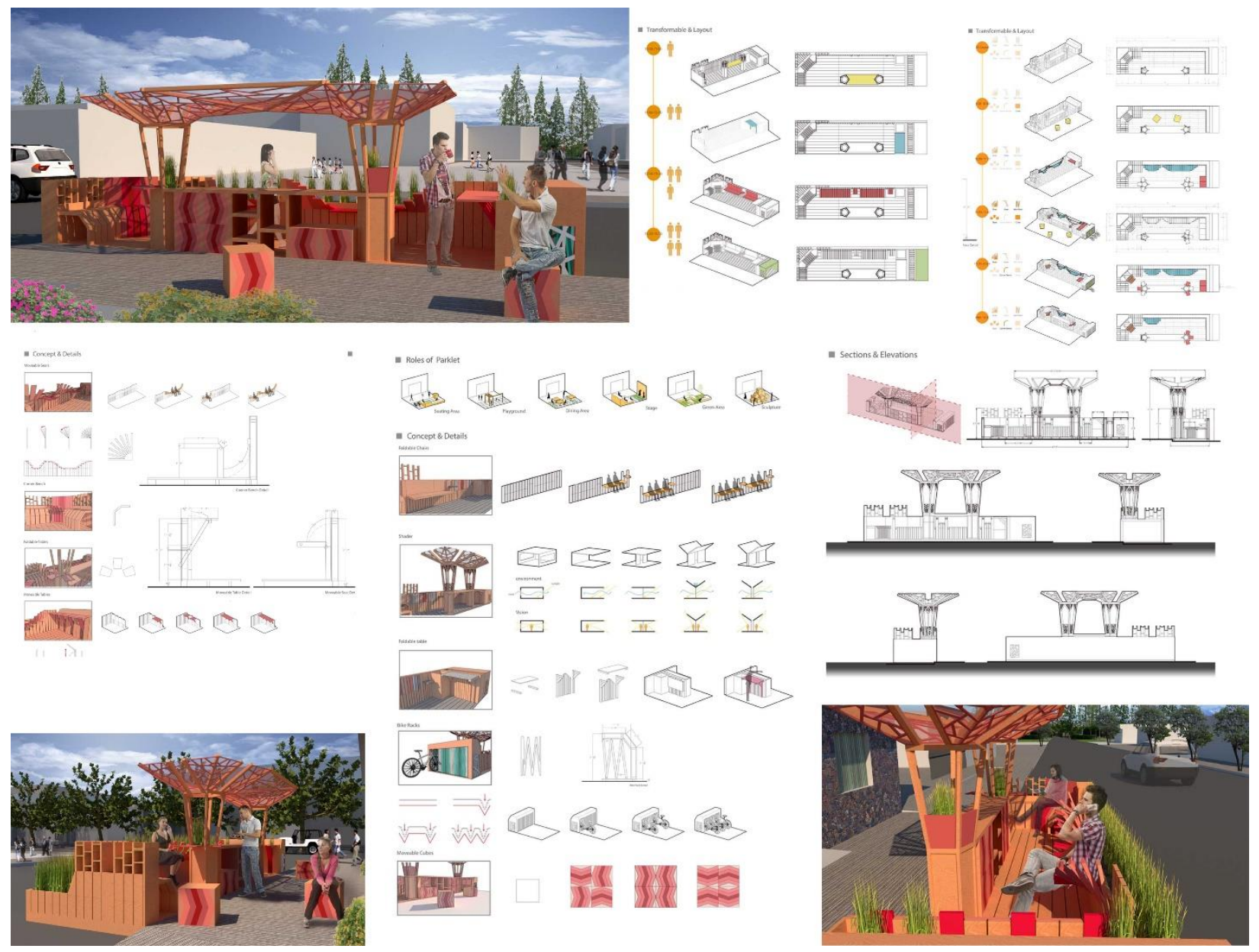

Figure 2. Selected Project that was built in full-scale

\section{Phase 3: Design Development and Fabrication}

The whole class worked collaboratively in the remaining eight weeks to develop, document, prototype, and make the details ready for the fabrication of the full-scale project. students submitted a design proposal to the city which was permitted, meeting all the required codes and regulations such as ADA, fire codes, etc. Since the project's site was in another city, students prefabricated the pieces in school and shipped and assembled them at the site in one day. Considering the size of the truck, students should come up with solutions to ease up the transportation and storing the Parklet in the client storage. Students relied on parametric design to visualize and estimate the potential challenges of a project during the design stage. They used digital software simulators such as Kangaroo Physics 2 and Ivy plugin in Grasshopper for analysis of the stresses and potential weaknesses of the structure in a given situation. They took advantage of potentials embedded in digital fabrication tools and techniques to in addition to some consultants from a structural engineer and some construction management experts to prefabricate their Parklet.

The program allocation is the result of site analysis, existing programs, and sun/shadow analysis. This analysis helped us to come up with the location, height, length, patterns, and colors on the 
canopy's panels. The canopy was designed and located based on comprehensive sun path and shadow studies in the site. The pattern and color of the shaders, their location, and the size of the canopy panels were tectonically designed based on shadow analysis using EnergyPlus and Ecotech software. Embedded greenery creates fresh air and cools the space. Other environmental considerations include water collection methods which collect and distribute rainwater to irrigate greenery embedded on each side of the Parklet and in the middle of each canopy. Considering the
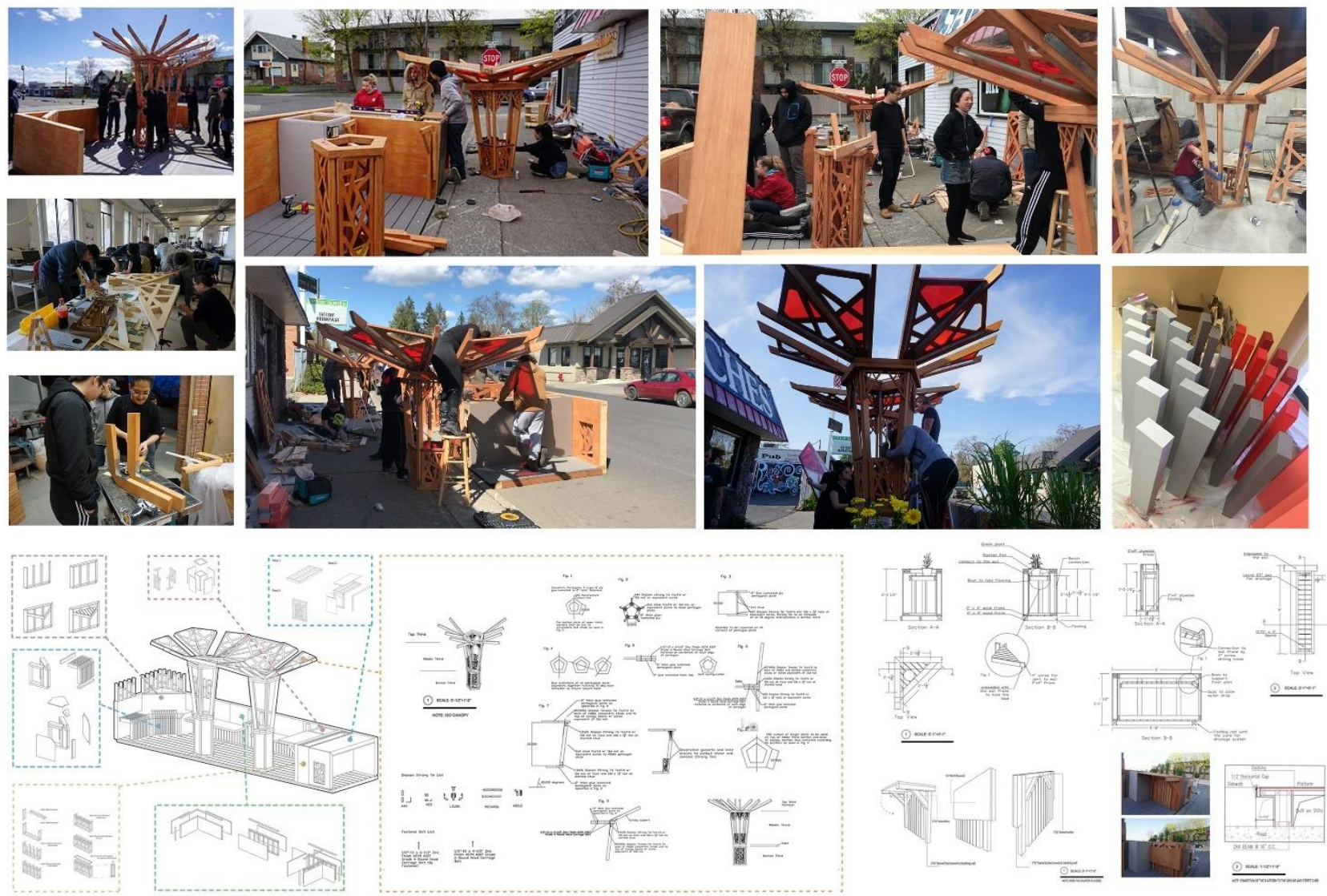

existing slope of the site and design insight in slopping the canopy, the water can be collected from the canopy 's panels to irrigate the plants in the Parklet. (Figure 3)

Figure 3. Construction process and details | students developed the details and fabricated the Parklet collaboratively

\section{RESULT}

We designed a transformable Parklet that can reconfigure its space and integrated furniture based on various events, needs of the people in the neighborhood, or a number of people. Flexible and transformable furniture embedded in the Parklet could gradually morph based on various program and user's needs and improve the efficiency of space usage at different times. This Multi-facetted usage of space is a driving force for the development of a vibrant, contemporary, and adaptive neighborhood. The final result is a pleasant human-centered urban space that plays with light and colors and offers a delightful area for gathering and socializing while benefiting the neighborhood and local businesses. This Parklet is sponsored and maintained by a woman-owned business who is active in preventing child trafficking. It is designed and fabricated in full-scale in one semester, exposing students to computational design, digital fabrication and the whole idea of design-build 
projects for the first time. (Figure 4) as future work, to evaluate the success of the project, we will consider a research to assess the influences of the Parklet in social interaction between pedestrians in the neighborhood, what the people think about it, and how it helps the local business.
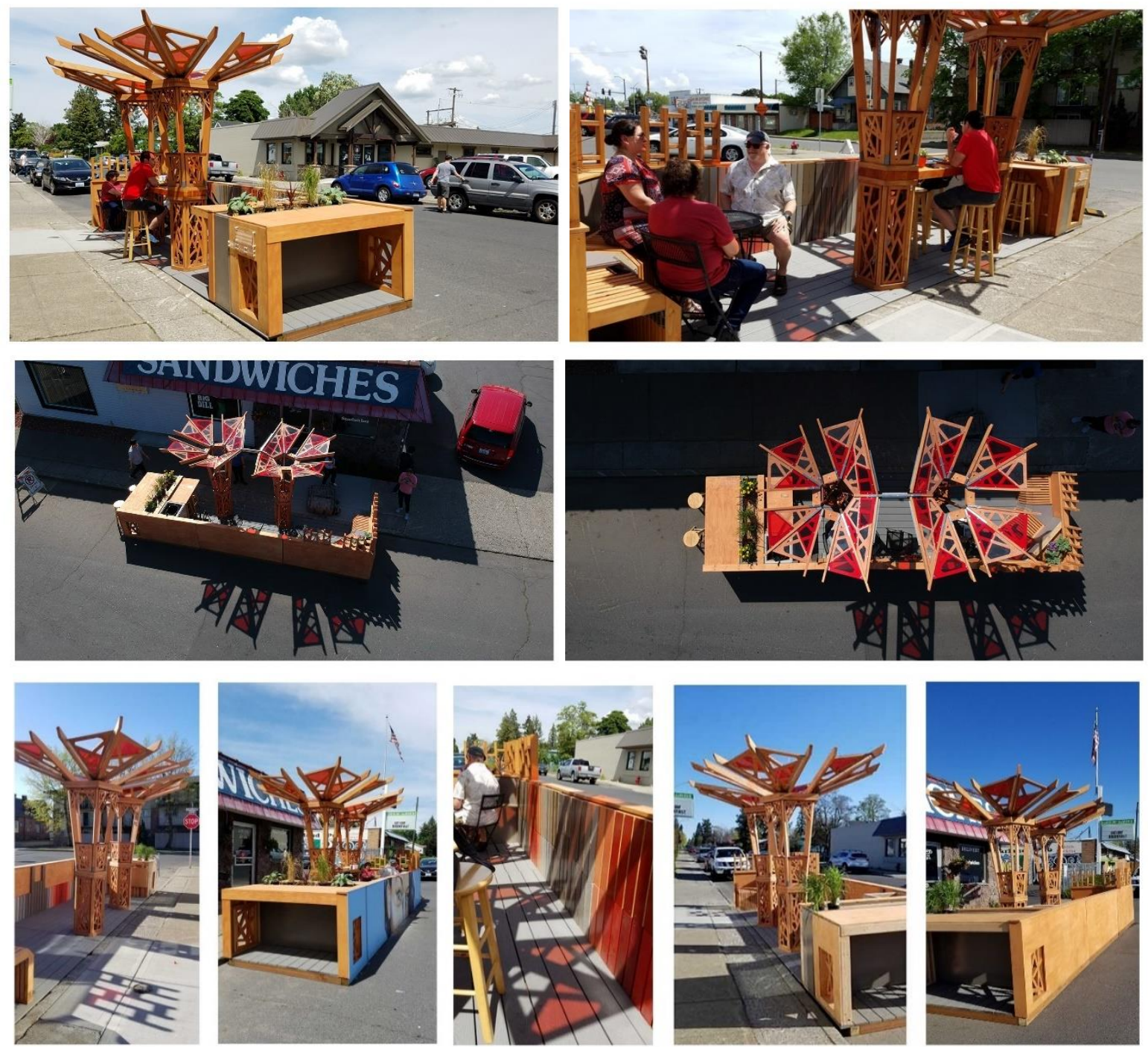

Figure 4. The final result of the Parklet and people/neighborhood interaction with the Parklet

\section{CONCLUSION}

In this studio, emerging technologies were used in the service of advancing architectural design education and social justice. Students identified proper methods of design inquiry and problemsolving processes to generate creative solutions to real-life issues. They synthesized information from multiple sources to establish design parameters and develop genuine conceptual frameworks. They also applied research, theory, design precedents, regulations, and established conventions as appropriate to inform design decisions. What emerged was a Parklet intended as a focal point for increased foot traffic and informal encounters, bolstering positive feelings of camaraderie and community. This studio represents the application of computational design and digital fabrication strategies and how they can be used in a pedagogical framework to nurture student's creative 
capacities. The studio encouraged students to adopt emergent technologies as a strategy to reinterpret architecture in the service of social good.

\section{ACKNOWLEDGMENTS}

Special thanks to my undergraduate junior students, Spring 2018, who designed and built this project and to My TA Hamidreza Esmaeillou. This research project has been supported financially by the Inland Northwest Architectural Foundation, Integrus Architecture, Pullman Building Supply, Garland Sandwich Shoppe, Bernardo Wills Architects, MMEC Architecture and Interiors, and ALSC Architects. We appreciate their support without which the construction of this project wouldn't have been possible.

\section{REFERENCES}

Abad Ocubillo, R. (2012). Experimenting with the margin: Parklets and plazas as catalysts in community and government (Unpublished master's thesis). Thesis / Dissertation ETD.

Retrieved from

http://digitallibrary.usc.edu/cdm/compoundobject/collection/p15799coll3/id/89034/show/8 8789

Appleyard, D. (1973, June). Professional Priorities for Environmental Psychology. In Küller, Rikard (ed.), Architectural Psychology: Proceedings of the Lund Conference: June 26--29, 1973. Stroudsburg, PA: Dowden, Hutchinson, and Ross.

Chermayeff, S. and Alexander, C. (1963). Community and Privacy: Toward a New Architecture of Humanism. New York, NY: Doubleday.

Davis, M. (1990/2006) City of Quartz London: Verso Books.

Grunewald, K. (2013, April 28). Student Society of Landscape Architecture demonstrates parklet. Retrieved from http://www.iowastatedaily.com/news/article_d8fd6008-adf7-11e296a3-001a4bcf887a.html

Harvard Health Publishing. (n.d.). The health benefits of strong relationships. Retrieved from https://www.health.harvard.edu/newsletter_article/the-health-benefits-of-strongrelationships

Jacobs, J. (1961/1989). The Death and Life of Great American Cities. New York, NY: Vintage Books.

Lee Jr., Douglas B. (1973, May). Requium for Large--Scale Models. Journal of the American Institute of Planners, Vol 39, Number 3.

Miller, R. (2012, Winter) Parklets: Turning Parking Spaces into Parks. The New Planner.

Parklets. (n.d.). Retrieved from https://my.spokanecity.org/projects/parklets/

Sadik--Khan, J. (2011, June 7). NYC's Plaza Program, An Open Space Model for L.A.? retrieved from Los Angeles Streetsblog: http://la.streetsblog.org/2011/06/07/nycs-plaza-program--an-open--space--model--.for-1--a/

SAN FRANCISCO PARKLET MANUAL. (2013, February). Retrieved from https://web.archive.org/web/20130425020459/http:/sfpavementtoparks.sfplanning.org/docs /SF_P2P_Parklet_Manual_1.0_FULL.pdf.

São Paulo Replaces Parking Spots with Mini 'Parklets' for a More Pedestrian-Friendly Urban Environment. (2014, July 14). Retrieved from http://inhabitat.com/sao-paulo-replacesparking-spots-with-mini-parklets-for-a-more-pedestrian-friendly-urban-environment/

Seligman, K. (2011, June 19). San Francisco's tiny plazas convert parking to parks. The Sacramento Bee 